\title{
Ageing and generational effects on vote choice: Combining cross-sectional and panel data to estimate APC effects
}

This paper examines how ageing and generational formative experiences affect vote choices in Britain. Using a combination of panel data and assumptions about party fortunes we estimate ageing effects. These are then entered into a model using cross-sectional data from 1964-2010 to estimate generational differences in vote choice. Ageing increases the likelihood of a Conservative vote substantially, but there is no trend towards lower rates of Conservative voting among newer generations. There are however identifiable political generations corresponding with periods of Conservative dominance: voters who came of age in the 1930s, 1950s and 1980s are ceteris paribus somewhat more Conservative. Our method lends some support to theories of political generations, but also demonstrates the considerable impact of ageing on vote choice.

\section{Keywords}

Vote choice, Britain, ageing, generations, APC models.

\section{Highlights}

Combining panel and cross-sectional data helps to identify APC effects.

As people age they become more likely to vote Conservative.

There are identifiable political generations in Britain, but these effects are small. 
In keeping with the goals of this special issue we present a method for dealing with the longstanding problem of making inferences about age, period, and cohort (APC) effects on political choices. Our approach is empirical rather than statistical in that it makes use of 'side information' (Glenn 1976, 2005) to help identify the effects of ageing in panel studies and inputs these estimates into conventional cross-sectional models. The term side information (see also Converse 1976) simply refers to the use of information from outside of the cohort table to enable interpretation of otherwise under-identified combinations of age, period and cohort influences. ${ }^{1}$ By estimating ageing effects using panel data in conjunction with information on aggregate election results we hope to provide side information that uses assumptions that are transparent, as well as defensible, and that other researchers are able to evaluate. We focus on an unresolved debate in the study of British electoral behaviour for which relatively good quality panel data over a considerable time period is available. Given the growing number of panel studies conducted elsewhere the method has the potential to be applied to vote choice in a range of other democracies. Our aim is also broader than this though. We hope to show that using side information from outside the original dataset in a systematic manner is a good way of trying to disentangle APC effects, as it forces researchers to make explicit the assumptions that are always necessary in this type of endeavour.

Substantively the paper examines the origins of the relationship between age and vote choice. In Britain age is a strong predictor of vote choice, with older people much more likely to vote for the Conservatives and younger people much more likely to vote for Labour or the Liberal

\footnotetext{
${ }^{1}$ An alternative approach is to use strong theoretical assumptions about political learning processes such as those adopted by Bartels and Jackman (2014) in this special issue. In general, making such strong theoretical assumptions is often difficult. Certainly in this case we have several different theoretical approaches that suggest competing ageing and generational effects.
} 
Democrats. This relationship has been a commonly remarked upon feature of the British political landscape for many years. Less clearly understood, however, are the processes that produce this observed association. We discern four types of process that can account for an observed relationship between age and vote. Two relate to ageing itself and two to the process of political socialization, and hence generational effects.

Ageing effects can derive from processes inherently related to getting older, such as psychological changes relating to values and preferences. Ageing has been linked with increasing conservatism and authoritarianism (Wilson 1973; Feather 1977; Truett 1993), cognitive inflexibility or close-mindedness (Jost et al. 2003; Kruglanski 2005) and long-term attitude stability indicative of a resistance to change (Alwin et al. 1991; Alwin and Krosnick 1991; Neundorf et al. 2011). These and other personality-related attributes have been argued to account for the association between age and conservative values (Cornelis et al. 2009) and by extension they could also account for the link between age and Conservative voting.

Age effects can also derive from social changes that occur over the life-cycle, as people get jobs, get married, have children and retire, all of which may influence political orientations through their impact on investments and resources (Binstock and Quadagno 2001). These changes are also likely to influence perceived interests and levels of stake in the status quo, and thus produce insecurity with respect to changes to that status quo (Williamson et al. 1982). Again, these processes have been thought to make voters likely to support parties on the right.

To the degree that ageing effects derive from either of these psychological or social ageing processes they carry no negative implications for future support for the Conservative party in 
Britain as they simply imply that each generation gets more Conservative as they age. Indeed, given the ageing demographic profile of the population they could imply the opposite becoming older makes people more Conservative and the proportion of the electorate that is old is steadily increasing as life spans lengthen.

Generational effects can also be attributed to two distinct sources of influence, with differing implications for the pattern of change. First, there are long-term processes such as increasing social liberalism among younger cohorts (Danigelis and Cutler 1991; Ford 2011; Tilley 2002, 2005) in part, but not only, because of the pronounced growth of tertiary education and its effects on liberal values (De Graaf and Evans 1996; Evans 2002). More generally others have pointed to the growing importance of postmaterial values through generational replacement (Abramson and Inglehart 1995; Inglehart 1997). This process of generational replacement is potentially significant electorally, as it implies that right-wing parties are fighting against 'the tide of history' on social liberalism - the positioning of the current UK Prime Minister and leader of the Conservative Party in favour of gay marriage would seem to reflect an acceptance of and response to this tendency. If generational replacement produces a more progressive electorate, as has been argued in the United States (Judis and Texiera 2002; Klinkner and Schaller 2008), then there will be a continued pressure on the Conservative Party to either become more progressive or to accept a likely social democratic hegemony. This process is plausibly at the root of any observed linear cohort effect on vote choice and provides a clear alternative to an interpretation in terms of ageing.

Second, there are specific generational differences that derive from the party political context in the period when people enter the electorate. As voters come of age at times when different parties are successful and different issues are salient, they can be characterized as forming 
more or less distinct political generations. Their long-standing political preferences may therefore reflect the dominant political forces present during the period when they came of political age. If a particular party is dominant during a voter's formative years they may carry that predisposition with them throughout their electoral career. This view has typically been elaborated by authors advocating the 'Michigan model' of voting behaviour, for whom voting decisions are derived from long-term affective attachments to political parties learned during early adulthood which stabilize over the life-course. ${ }^{2}$ The years in which voters enter the electorate are argued to be highly consequential: 'new voters are flexible/unstable and much more responsive to new events than are older voting cohorts' (Converse 1969: 143). This view is reiterated on the basis of extensive empirical analysis of more recent US data by Green et al. (2002: 107-108): 'The influences of the political environment are most noticeable among young voters, whose partisan attachments often bear the stamp of the political Zeitgeist that prevailed when they reached voting age' and, from a different perspective, by Erikson, Mackuen and Stimson (2002: 186): 'When political events favor one party over the other, the response is generally felt among all birth cohorts, with the strongest amplitude among the young.' The presence of such political generations implies that generational differences cannot safely be assumed to favour a monotonic trend, whether socially liberal, anti-Conservative or otherwise. To the degree that the fortunes of the major British political parties over the last century have not varied systematically with cohorts, we would not expect to find linear generational effects. ${ }^{3}$

\footnotetext{
2 Authors in this tradition have also emphasized parental attachments as an important source of party identification for new voters (McAllister and Kelly 1985; Jennings et al. 2009; Niemi and Jennings 1991).

${ }^{3}$ The increasing presence of Labour governments in recent decades when compared to the early part of the $20^{\text {th }}$ century can be expected to have shaped recent cohorts' political orientations in a left-wing direction, which could in principle account for a tendency for cohorts to be less Conservative over time. A monotonic decline in Conservative vote among very recent cohorts may not reflect long-term value change, but simply the workings
} 


\section{Previous studies}

Previous empirical research into ageing and generations in Britain and the United States has tended to point to the presence of distinct cohorts of voters and to interpret age differences in these terms. As early as the 1970s, most US researchers concluded that differences in partisanship were generational (Glenn 1974; Abramson 1976; Converse 1976). The 'Depression generation' that came of age in the 1930s was different from preceding and following cohorts. The cohorts that came of age in the 1920s and 1940s were moulded by different forces and had not undergone the same experiences of Roosevelt's New Deal. Similarly in Britain, the nature of age-related differences in party choice were first examined by Butler and Stokes (1974), who proposed that these differences were due to differing formative experiences, i.e., generational effects, rather than an ageing process linked to increasing Conservatism. In Britain since then the conventional view has been that there was a World War II (and especially 1945) Labour generation and in the 1980s a Thatcher generation, and these have been argued to form distinct political generations (Butler and Stokes 1974; Thorburn 1977; Russell et al. 1992; Tilley 2002; Goerres 2007). Similarly, in the US there was argued to be a 'New Deal generation' of Democrats that came of age in the 1930s (Campbell et al. 1960; Converse 1976; Miller and Shanks 1996) and a (Republican) 'Reagan generation’ of the 1980s (Norpoth 1987; Green et al. 2002). In Russell et al.’s (1992) study of 'Thatcher's children' in Britain, it was argued that political socialization during Thatcher's term in office meant that first-time electors in the 1979 and 1987 elections were more Conservative than would be expected given their youth. They were: “Thatcher's

of early political socialization under recent periods of Labour incumbency. The estimation of political generations allows this possibility to be evaluated. 
children”. ${ }^{4}$

We therefore have the following distinct narratives to unravel.

1) Does ageing make people more Conservative? If so:

a) Are ageing effects due to the psychological mechanisms described earlier?

b) Are ageing effects attributable to life-cycle factors?

2) Do formative experiences affect Conservative support? If so:

a) Are generational effects reflecting processes of social change and an increasingly liberal population?

b) Are there distinctive political generations?

We test these in different ways: 1a and 2a suggest a linear ageing effect (younger people are less Conservative) and a linear generational effect (newer generations are less Conservative) respectively; 1b suggests that controlling for social characteristics (like being married, or levels of income) should eliminate any social ageing effects; $2 b$ suggests that any generational effects will be non-linear and related to political events experienced in voters' formative years.

\section{Using panel data to estimate ageing effects}

Distinguishing generational change from ageing is problematic when using only repeated

\footnotetext{
${ }^{4}$ Though it is important to note that Russell et al.'s (1992) study also showed that ageing leads to increasing support for the Conservative party. As with many other studies, however, their emphasis was on revealing generational effects.
} 
cross-sectional survey data. The identification problem is well-known: the three processes of age (A), period (P) and cohort (C) cannot be distinguished. Once we know a birth cohort's age, then we know the period in which the survey was taken; once we know the period of the survey and the respondent's age we know his birth cohort; and if we know his age and birth cohort then the survey period is known.

Identifying any of the three confounded effects is not possible without imposing restrictions on the model. These can be simple and transparent restrictions such as setting one of the APC effects to zero, or they can be more complex, and often less transparent, restrictions which force effects to comply with certain, often untestable, statistical assumptions (Yang et al. 2004, 2008). Some have argued that attempting to devise increasingly complex restricted statistical models is a flawed approach however. Rather, cohort analysts should concentrate much more on the quality of the 'side information' they are using to provide those restrictions. The main exponent of this view, Glenn (1976; 1977; 2005), argues that statistical 'solutions' to the identification problem are inherently flawed. We also think that a focus on the quality of assumptions about the restrictions within a model can be very helpful. And so what we do here is not attempt to provide statistical resolution of the APC problem, not least because that is impossible, but rather demonstrate how using different sources of high quality side information in a systematic way, along with certain transparent assumptions, can allow us to make inferences about the nature of APC effects. Specifically, and elaborating on a technique used by Tilley (2003), we estimate the minimum and maximum possible strength of ageing effects using panel data, and then introduce those estimates into a model using cross-sectional data to identify generational and period effects.

\section{Data}


As mentioned, we use two sorts of data in this paper, pooled cross-sectional data from twelve of the set of thirteen British Election Studies (BES) $)^{5}$ carried out in the every general election year since 1964 and a series of seven different panel studies. Five of those panels are British Election Study panels, carried out between 1966-70, 1970-February 1974, October 19741979, 1992-1997 and 2005-2010. The other two panels are the British Household Panel Study (BHPS), of which we examine the 1992-2005 waves and the National Child Development Study (NCDS) of which we examine the 1981-2008 waves. ${ }^{6}$ We restrict the analysis to England to avoid having to deal with the more complex party systems, and change over time in those systems, in Wales and Scotland; we also restrict the analysis to over 21s to make earlier surveys comparable with later ones; and finally include only respondents who report voting.

Our dependent variable is vote, categorised into Conservative, Liberal or Labour. Voters for minor parties are excluded. The key independent variables are age, cohort and election year, but in the cross-sectional analysis we also include a range of controls that may be linked to age/cohort and vote choice. These are: occupational class (salariat, routine non-manual, petit

\footnotetext{
${ }^{5}$ The 1983 BES did not ask a number of key questions so is not included.

${ }^{6}$ We use these wave comparisons as they are longest periods between elections. The BHPS is of a similar format to the BES panels, in that it follows a cross-section of the population over time. One important difference is that the survey is not fielded immediately after the election, but rather mainly in the September-December part of the year. The NCDS is not a representative cross-section, but rather follows a group of people all born in one week of March 1958. These people were then followed up in a number of waves. Here we compare the 1981 wave, which asks about vote choice in 1979 when respondents were aged 21 with the 2008 wave, which asks about vote choice in 2005 when respondents were aged 47.
} 
bourgeois, foremen/ supervisor or working class) ${ }^{7}$; income (top decile, 9th decile, 4th quintile, 3rd quintile, 2nd quintile or 1 st quintile) ${ }^{8}$; trade union membership (current or not current member); housing type (owner-occupier or not); educational qualifications (degree, some higher education, A-levels, more than minimum school leaving age, minimum school leaving age); sex; ethnicity (white or non-white); marital status (married/been married or single); region (North, Southwest, Midlands/ East or Southeast).

\section{Analysis}

The puzzle to be explained

Before trying to explain generational and ageing effects, we need to show that these are potentially real and interesting. Figure 1 shows predicted probabilities from a multinomial logistic model predicting vote choice using the pooled set of twelve British Election Study surveys. Included in this model are the year of the election, generation and a series of control variables. Generation is operationalised as 'coming of age' year, which is banded into twoyear cohorts. These cohorts are coded as the year at which a respondent reached the age of 21. Thus crucially this model assumes no ageing effects, but also, since generation and year

\footnotetext{
7 Occupational class is derived from the 19 category socio-economic group (SEG). A small number of respondents did not have a SEG classification, but were able to be classified due to information on their employment status and managerial status. Individuals not currently working as a result of, for example, unemployment or retirement, are assigned to their last occupation, and those who had never had a job or who were unable to be assigned to a class were assigned to their husband or wife’s class.

${ }^{8}$ The income figures generally refer to household income for any respondent, although in a few of the earlier surveys it is the head of household income. As the question on income in all the BESs is categorical, we are not precisely placing respondents on an income scale, but rather fitting nearest categories into each of the quintiles and two top deciles. Finally we should note that income quintiles are referenced to the individual survey sample, so the bottom quintile refers to the bottom income quintile in the survey, not necessarily in the population.
} 
are both categorical, allows period effects for each election and a non-linear pattern of generational difference. Finally we include the control variables detailed above that may be correlated with vote and cohort/age.

\section{FIGURE 1 ABOUT HERE}

Figure 1 shows the percentage of people predicted to vote Conservative by coming of age year. We plot this separately for three different election years (as very few people born prior to the 1920 s were alive to vote in the 2010 election, and no one born after 1943 was eligible to vote in 1964). ${ }^{9}$ The lines $\mathrm{n}$ the graph are 3-period moving averages that remove some of the 'noise'.

Three things are immediately apparent from Figure 1. First, assuming no ageing effects results in very strong generational effects. In 1987 around three quarters of the oldest cohort coming of age in the early 1930s were estimated to have voted Conservative compared to less than half of those in the youngest cohort that came of age in the 1980s. If we were to imagine that someone coming of age in 1910 were still alive to vote in 2010, we would predict that they had an 80 per cent chance of voting Conservative compared to only 40 per cent for someone that came of age in 2000. Thus if one assumes no ageing effects, the reduction in the Conservative vote share over time is due to generational replacement, period changes between 1987 and 2010 made little difference to the Conservative vote share. This is shown by the fact that people who came of age in the 1960s voted Conservative at the same rate in

\footnotetext{
${ }^{9}$ The control variables have to be held constant, and thus the predicted probabilities are for a white man in the second income decile with no qualifications, who lives in the Midlands, is married, is in the routine non-manual occupational class, does not belong to a trade union and is an owner-occupier.
} 
the 1987 and 2010 election.

Second, while there is no period effect between 1987 and 2010, there is between 1964 and 1987. If we examine those people that came of age in 1960 (who were able to vote in all three of the elections that we look at here), it is the 1964 election which stands out. The cohort that came of age in 1960 voted about 60 per cent Conservative in 1987 and 2010, but only 50 per cent Conservative in 1964. These are perhaps not the election effects that we might expect, as 1964 is not normally seen as the nadir of Conservative electoral success.

Third, the generational effects we see are not linear. Although newer cohorts are generally much less likely to be Conservative, there are some interesting patterns to the generational changes that may map on to political changes in Britain during those cohorts' formative years. Those coming of age in the early 1940s seem less Conservative than the cohorts that surround them, as do those coming of age in the late 1960s and 1970s. These patterns match the political context, with the realigning Labour landslide victory of 1945 affecting those coming of age in the 1940s, and the main period of Labour party rule in the twentieth century coinciding with the 1960s/1970s (Heath’s premiership aside).

Nonetheless, what Figure 1 most clearly reveals is that if there are no age effects, then generational effects are important. It also heralds bad news for Conservative politicians as their electorate appears to be dying out to be replaced by less Conservative voters. Of course, it is that assumption of no ageing effects that is critical and, as discussed, also debateable. Our next step is therefore to try and estimate ageing effects from a source outside the crosssectional data. We can then put those estimates back into our model and 'correct' the generational patterns to account for ageing as well. 


\section{Panel and aggregate data}

We estimate those ageing effects using a combination of panel data and information on aggregate election results. By tracing patterns of vote change over a panel of voters we see a combination of period effects (say due to a change of leader or party policies) and ageing effects. By then accounting for those period effects using aggregate vote changes between elections we can measure the range in which ageing effects can be assumed to lie. Having measured ageing effects, we can use the cross-sectional data to model generational and period effects accurately. So there are two initial steps: first, calculate the change over time for a particular panel; second, calculate what part of that change is period change. The first is relatively easy; the second less so. We effectively have two equations, as below, for our two different sources of data.

For the aggregate election return data:

Change over time in Conservative support $=$ period change + generational replacement

For the panel data:

Change over time in Conservative support $=$ period change + ageing

As we have three terms that are not measured and only two equations, we cannot solve this. But by making a couple of assumptions about the direction of certain changes, we can get maximum and minimum estimates of ageing effects. What we need to assume is period effects between certain elections are positive and between other elections are negative, and that any generational replacement reduces Conservative support. The second of these seems relatively innocuous - it seems reasonable to assume that if there is a trend for new generations to be systematically different from older generations then this means that the 
newest generation will be less Conservative than the oldest generation. ${ }^{10}$ The first is more restrictive as it means that we can only examine changes between elections where we are confident that we know what any period change was. Nonetheless that leaves a number of election pairings where we can make a reasonable assumption of the direction of change. In particular, we assume that the Conservatives increased their support due to period factors between 1966 and 1970, between 1974 and 1979, and between 2005 and 2010. We also assume that the Conservatives lost support between 1970 and 1974, between 1992 and 1997, between 1992 and 2005 (the dates of the British Household Panel Survey) and between 1979 and 2005 (the dates of the National Child Development Study).

If we take the 1974-79 period as an example, by assuming that any period change that increases Conservative support is a 'positive' change, then the change we observe in the aggregate election returns provides us with a minimum estimate of that period change. It is a minimum because any generational replacement would be reducing Conservative support and any period changes would be increasing Conservative support: therefore the actual period change can only be the same or higher than that which we observe in the aggregate data. Taking that as the minimum period change means that we are able to work out what the

\footnotetext{
${ }^{10}$ It is possible that non-linear effects of political context could provide a situation in which the oldest cohort leaving the electorate is less Conservative than the newest cohort that is entering. In reality, and as Figure 1 shows, there are only a handful of occasions when this could be the case, and any differences between the entering and leaving cohorts would be very small. If we ignore the linear trend, the effect of the replacement of a leaving cohort by an entering cohort will be negligible as the difference between the entering and leaving cohort will be so small. For example, ignoring any linear trend the difference between the 1940s cohort and the cohorts surrounding them is only a few percentage points. Replacing a five year cohort with another one that is 2 percentage points more Conservative will only lead to a maximum aggregate change of 0.03 percentage points per year.
} 
maximum ageing effect is from the panel data (as the panel change is the period change plus the ageing change, both of which are positive). So for the 1974-79 period the Conservatives obtained 40 per cent of the vote in February 1974 and 47 per cent of the vote in 1979, a 7 per cent increase. The panel data show a 10 per cent increase however, suggesting that the maximum ageing effect over those 5 years was a 3 per cent shift towards the Conservatives, or around 0.6 per cent per year. ${ }^{11}$

We can do something similar when thinking about a period in which Conservative support fell, so let's take the 1979-2005 period covered by the NCDS. Here we assume that period factors, whether due to unpopular policies, perceived lack of competence or poor leadership, reduced the Conservative vote share. That means the aggregate change from 47 per cent of the vote in 1979 to 36 per cent of the vote in 2005 is a maximum period change, because any generational effects will reduce the proportion of that negative change due to period effects. The actual change in the panel was less than half of that, around 5 per cent, meaning that we can estimate the minimum ageing effect over those 26 years was a 0.26 per cent shift towards the Conservatives per year.

By calculating these minimum and maximum values of ageing effects for a number of panels we can try and narrow down the range in which the actual ageing effects lie. The first step is therefore to measure the change over the course of several different panels, the second to measure the aggregate change in vote share over the same period, and the final step to combine these two to get for some panels estimates of maximum ageing effects, and for other

\footnotetext{
${ }^{11}$ We should note that it is a little more complicated than this, as the panel is a sample of the electorate. That means any change we see in the panel includes sampling error. Nonetheless the 10 per cent increase here is our best estimate of any change.
} 
panels estimates of minimum ageing effects. Table 1 shows the average change per year towards the Conservatives over the course of the seven panels that we analyse, the average change per year for the aggregate data over that period, and finally our estimates of those maximum and minimum ageing effects.

\section{TABLE 1 ABOUT HERE}

So if we take the average of the three panels that estimate maximum ageing effects, we arrive at a 0.38 per cent increase in Conservative voters per year, and the average of the minimum ageing effects is only somewhat lower at 0.32 per cent per year. These may not sound like very large effects, but over the course of a lifetime they add up. Even if only the minimum estimate is correct, the difference between 20 and 80 year olds is nearly 20 percentage points. These estimates are not radically changed by splitting the NCDS and BHPS panels into smaller chunks as well (shown in the Appendix table A1). As the minimum ageing effects are not that different from the maximum ageing effects, and these should only be equal when there is no generational replacement, we might already want to tentatively conclude that generational replacement is having very little effect on the share of the vote that the Conservatives gain.

\section{Combining panel and cross-sectional data}

We can include our ageing estimate in the previous cross-sectional models, and the suggestion that the effect of generational replacement is zero or near to zero is confirmed when we 'correct' our previous predictions of Conservative vote to include the minimum ageing effects that we estimated above. Figure 2 shows what the generational effects look like after we have take into account the estimate that ageing effects move voters 0.32 percentage 
points per year towards the Conservatives over their lifespan.

\section{FIGURES 2 AND 3 ABOUT HERE}

This correction is done by simply taking the cohort's age at the election year, so the cohort that was born in 1923 and was surveyed at the 1964 general election would be 41, and then removing the effects of ageing. For the 41 year olds in 1964, that would mean 20 years of ageing would produce 6.4 per cent (20 multiplied by 0.32 ) more Conservatives. Therefore in 1964 the difference between 21 year olds born in 1943 and 41 year olds born in 1923 is partially due to age effects, and those age effects are estimated to be 6.4 per cent. Turning to Figure 2 where these age effects have been removed, we see some striking patterns. First, there is no longer a change towards less Conservative voting amongst newer cohorts. The differences that appeared in Figure 1 are actually largely accounted for by ageing. Second, 1964 and 1987 now look much more similar and it is in 2010 when the Conservatives record the lowest vote share amongst the cohort that came of age in 1960 (and who were able to vote in all three elections). It is thus not generational replacement that has reduced the Conservatives' share of the vote over time, but rather period effects. ${ }^{12}$ Nor are these patterns much different if we take the maximum ageing effect. Figure 3 shows this, and unsurprisingly given the very similar maximum and minimum numbers, this is almost identical to Figure 2 .

Finally, both Figures 2 and 3 show that while there may be no linear generational trend, there are some small generational effects. Those that came of age after the war and in the 1970s are

\footnotetext{
12 The critical period effect is in 1997, when Conservative support dropped substantially. Since 1997 Conservative support has drifted slowly upwards due to positive period effects, although as the figure shows in 2010 it was still substantially below the 1987 level for any particular cohort.
} 
the least Conservative (taking the election year as 1987: 47 per cent for people that came of age in 1945, and 48 per cent for the 1975 cohort), and the most Conservative are those that came of age in the 1930s, the 1950s and the 1980s (taking the election year as 1987: 54 per cent for the 1933 cohort, 51 per cent for the 1959 cohort and 53 per cent for the 1987 cohort). Formative experiences in that sense matter, but the scale of those differences is clearly much smaller than the huge differences between cohorts that we saw in Figure 1.

\section{Conclusion}

Ageing makes people more likely to vote Conservative. The question of whether future Conservative support is threatened by generational replacement can therefore be answered with some confidence in the negative. Newer generations are not less Conservative than older generations once ageing effects are controlled for using side information taken from the panel studies. There are nonetheless identifiable political generations. Individuals born in certain years appear more or less Conservative, ignoring trend effects, depending on the prevailing political conditions at the time that they entered the electorate. The more Conservative cohorts were those that came of age in the 1930s, 1950s and 1980s. These were all periods of Conservative rule, and periods when Conservative beliefs were most notably in the ascendency. However, these effects are extremely small. Also, as they are non-cumulative in form they do not account for longer-term trends in Conservative support.

In general our findings point to a positive message for the Conservative party: as people age, they are more likely to vote Conservative. This is not a disguised consequence of generational replacement. Given the increasing longevity of the electorate and the increased proportion who are elderly, our findings indicate that over time we should expect to see, ceteris paribus, an increasingly Conservative electorate. Given the age differences in turnout, which is higher 
among older people (Goerres 2007), this demographic benefit is doubly beneficial. So although the main question raised at the beginning of this paper concerned not only the differing explanations given for obvious age differentials in Conservative support, but also the existence of distinctive generations with particular voting tendencies, our take-home message is that political generations matter, but only to a small degree. The changing sizes of demographic categories produced by an increasingly ageing population may well be more consequential. Even in an era of pension retrenchment, given that our estimates control for income levels, the greying of politics (Goerres 2009) may be good news for the Conservatives. The elderly are not Conservative because they are rich, but because they are elderly.

To obtain these conclusions we have had to make certain assumptions. Hopefully these are transparent, and our method more generally is an example of how using side information systematically can enable political scientists to answer questions about APC effects. Nonetheless they are assumptions. The first is a linear ageing effect. We believe this assumption is not necessarily problematic as we control for possible non-linear aspects of the life-cycle such as job changes, income changes and marital status. In principle, we could try and analyse non-linear age effects by tracking changes for particular age groups within the panel data. In practice, given there is already inaccuracy and variability in the quality of the different panel studies used, this is not really possible. ${ }^{13}$ The second is the possible direction of the generational and ageing effects. In order to measure maximum and minimum effects

\footnotetext{
${ }^{13}$ Unfortunately it is also difficult to include other panel data in the analysis, as we do not know the direction of period change between say 1983 and 1987. Also other existing panels have their own problems: the 1983-1987 British Election Panel Study has a very low N and the aggregate voting figures for the 1987-1992 period are affected by the impact of the poll tax on voter registration.
} 
from the panels we had to assume that ageing does not decrease Conservatism and similarly that generational replacement does not increase Conservatism. While this does not seem unreasonable in the British context, it clearly could be in other countries. Third, we do not include non-voters in our analysis. Our primary reason for not doing so is that it is much more difficult to make assumptions about the direction of turnout change (most of which between elections are relatively small), ${ }^{14}$ but this is nonetheless a limitation.

Moreover, there are limits to the generalisability of our substantive findings, although hopefully not our methodological approach. By focusing on the British (or more precisely, English) case, which has experienced relatively little change since the 1930s, we are necessarily limiting the size of the generation effects that we can find. In different contexts, where political change is more marked, so are the effects of belonging to a political generation. In Northern Ireland, for example, Tilley and Evans (2011) reveal generational effects that are of substantial magnitude even when key differences between generations on the major political issue of nationalist versus unionist ideology are controlled. The muted magnitude of the political generations revealed in the current analysis possibly owes something to the relatively non-polarized nature of British politics and party change over most of the period examined. The age effects we have identified might well be less

\footnotetext{
${ }^{14}$ It seems likely that if we were able to account for turnout changes, they would not radically affect our results however. Firstly, this is because many people are consistent non-voters. If we take the NCDS panel from 19792005, then of the 18 per cent of people that reported not voting in 1979, almost half did not vote in 2005. Equally of the 23 per cent of non-voters in 2005, over 40 per cent were non-voters in 1979 . Secondly, the 1979 non-voters that did vote in 2005 look very similar to the overall distribution of voters from the panel in 2005. Similarly, the people that became non-voters in 2005, but had previously voted in 1979, while slightly more likely to be Labour voters in 1979 than the overall population, do not look radically different from the general distribution of voters in 1979.
} 
substantively dominant in more turbulent electoral environments. ${ }^{15}$

In addition, the mechanisms behind the ageing processes we find here are not entirely clear. While we can rule out some social ageing effects (due to marriage, income changes and so forth), we do not know exactly why people become more supportive of the right as they age. The psychological ageing literature focuses on conservatism with a small c, rather than the political implications of ageing. While a link between these is plausible, we have not directly tested how people's values and attitudes change over the life-course, and do not know whether it is increasing authoritarianism, increasing resistance to change, or changes to other personality related attributes that account for the relationship between age and Conservative support.

These caveats aside, we can nonetheless conclude that traditional cohort studies of voting behaviour that do not use estimates of ageing obtained from panel studies have seriously underestimated the importance of psychological ageing. Contrary to most previous cohort studies of British voting behaviour, the generational replacement thesis is not supported. Butler and Stokes (1974) and more recent work by Tilley (2002) made particular assumptions about the nature of period effects and found 'a linear trend for individuals born further from the present day to be more Conservative' (Tilley 2002, 134). We find no such trend. The only

\footnotetext{
${ }^{15}$ We might also note that our estimates of the importance of ageing for vote choice differ from those proposed by Bartels and Jackman (2014). Apart from the obvious difference in the electorates (English versus American) being examined, this difference follows inevitably from Bartels and Jackman's theoretically driven model, for whom a "key simplifying assumption ... is that age has no independent impact on political attitudes." This allows the authors to show how different age groups are differentially responsive to period effects (a necessary part of any generational story), but substantial age effects of the sort we have identified are precluded from being estimated.
} 
significant cohort effects are for the non-linearities associated with political generations resulting from periods of Conservative dominance. The key substantive message to be taken from our approach therefore is that ageing is the dominant influence on party choice. Standard approaches to APC problems tend not to focus on ageing effects, but their significance lies not just in explaining vote choices today but also in the implications they have for the future of party support. If people vote increasingly for the right as they age, then demographic trends clearly point to a growing Conservative electoral advantage. The population is living longer and getting older. The tide of history is in this sense moving towards the Conservatives, not away from them. If replicated by similar combined panel/cross-section studies elsewhere, our understanding of the relationship between age and party choice may need yet more extensive revision. 


\section{References}

Abramson, P.R., 1976. Generational change and the decline of party identification in America: 1952-1974. American Political Science Review 70, 469-478.

Abramson, P.R., Inglehart, R., 1995. Value Change in Global Perspective. University of Michigan Press, Ann Arbor, MI.

Alwin, D.F., Krosnick, J.A., 1991. Ageing, cohorts and the stability of socio-political orientations over the life span. American Journal of Sociology 97, 169-195.

Alwin, D. F., Cohen, R.L., Newcomb, T.M., 1991. Political attitudes over the life span: the Bennington women after fifty years. University of Wisconsin Press, Madison, WI.

Bartels, L., Jackman, S., 2014. A generational model of political learning. Electoral Studies (forthcoming).

Binstock, R.H., Quadagno, J., 2001. Aging and politics. In: Binstock, R.H., and George, L.K. (Eds.) Handbook of Aging and the Social Sciences. Academic Press, San Diego, pp. 333-351. Butler, D.E., Stokes, D.R., 1974. Political Change in Britain (2nd edition). Macmillan, London.

Campbell, A., Converse, P.E., Miller, W.E., Stokes, D.R., 1960. The American Voter. Wiley, New York.

Converse, P.E., 1969. Of time and partisan stability. Comparative Political Studies 2, 139172.

Converse, P.E. 1976. The Dynamics of Party Support: Cohort-analysing Party Identification. Beverly Hills, Sage.

Cornelis, I., Van Hiel, A., Roets, A., Kossowska, M., 2009. Age differences in conservatism: evidence on the mediating effects of personality and cognitive style. Journal of Personality 77, 51-88.

Danigelis, N.L., Cutler S.J., 1991. Cohort trends in attitudes about law and order: who's 
leading the conservative wave? Public Opinion Quarterly 55, 24-49.

De Graaf, N.D., Evans, G., 1996. Why are the young more postmaterialist? a cross-national analysis of individual and contextual influences on postmaterial values. Comparative Political Studies, 28, 608-635.

Erikson, R.S., MacKuen, M.B., Stimson. J.A., 2002. The Macro Polity. Cambridge University Press, New York.

Evans, G., 2002. In search of tolerance. In: Park, A., Curtice, J., Thomson, K., Jarvis, L. and Bromley, C. (Eds.), British Social Attitudes: The 19th Report. Sage, London, pp. 213-230.

Feather, N.T., 1977. Value importance, conservatism, and age. European Journal of Social Psychology 7, 241-245.

Ford, R., 2011. Acceptable and unacceptable immigrants: how opposition to immigration in Britain is affected by migrants’ region of origin. Journal of Ethnic and Migration Studies 37 (7), 1017-1037.

Glenn, N.D., 1974. Aging and conservatism. Annals of the American Academy of Political and Social Science 415, 176-186.

Glenn, N.D., 1976. Cohort analysts’ futile quest: statistical attempts to separate age, period and cohort effects. American Sociological Review 41, 900-904.

Glenn, N.D., 1977. Cohort Analysis. Sage, Beverly Hills.

Glenn, N.D., 1989. A caution about mechanical solutions to the identification problem in cohort analysis: comment on Sasaki and Suzuki. American Journal of Sociology 95, (3), 754761.

Glenn, N.D., 2005. Cohort Analysis, 2nd Ed. Sage, Thousand Oaks, CA.

Goerres, A., 2007. Why are older people more likely to vote? the impact of ageing on electoral turnout across Europe. British Journal of Politics and International Relations, 9, 90121. 
Goerres, A., 2009. The Political Participation of Older People in Europe: The Greying of Our Democracies. Palgrave Macmillan, Basingstoke.

Green, D., Palmquist, B., Schickler, E., 2002. Partisan Hearts and Minds.Yale University Press, New Haven, CT.

Inglehart, R., 1997. Modernization and Postmodernization: Cultural, Economic, and Political Change in 43 Societies. Princeton University Press, Princeton, NJ.

Jennings, M.K., Stoker, J., Bowers, J., 2009. Politics across generations: family transmission re-examined. Journal of Politics 71, 782-799.

Jost, J.T., Glaser, J., Kruglanski, A.W., Sulloway, F.J. 2003. Political conservatism as motivated social cognition. Psychological Bulletin 129, 339-375.

Judis, J.B., Teixeira, R., 2002. The Emerging Democratic Majority. Scribner, New York.

Klinkner, P.A., Schaller, T., 2008. LBJ's revenge: the 2008 election and the rise of the great society coalition. The Forum, 6(4), article 9.

Kruglanski, A.W. 2005. The Psychology of Closed Mindedness. Psychology Press, New York.

McAllister, I., Kelley, J., 1985. Party identification and political socialization: a note on Australia and Britain. European Journal of Political Research 13, 111-118.

Miller, W.E., Shanks, J.M., 1996. The New American Voter. Harvard University Press, Cambridge MA.

Neundorf, A., Stegmueller, D., Scotto, T., 2011. The individual level dynamics of bounded partisanship. Public Opinion Quarterly 2011, 75 (3), 458-482.

Niemi, R. Jennings, M.K., 1991. Issues and inheritance in the formation of party identification. American Journal of Political Science 35, 970-988.

Norpoth, H., 1987. Under way and here to stay: party realignment in the 1980s? Public Opinion Quarterly 51 (3), 376-91 
Russell, A., Johnston, R., Pattie, C., 1992. Thatcher's children: exploring the links between age and political attitudes. Political Studies 40, 742-756.

Thorburn, P., 1977. Political generations: the case of class and party in Britain. European Journal of Political Research 5, 135-148.

Tilley, J., 2002. Political generations and partisanship in the UK, 1964-1997. Journal of the Royal Statistical Society: Series A (Statistics in Society) 165(1), 121-135.

Tilley, J., 2003. Party identification in Britain: Does length of time in the electorate affect strength of partisanship? British Journal of Political Science 33(2), 332-344.

Tilley J., 2005. Libertarian-authoritarian value change in Britain, 1974-2001. Political Studies 53(2), 442-453.

Tilley, J., Evans, G., 2011. Political generations in Northern Ireland. European Journal of Political Research 50(5): 583-608.

Truett, K.R., 1993. Age differences in conservatism. Personality and Individual Differences, $14,405-411$.

Williamson, J.B., Evans, L., Powell, L.A., Hesse-Biber, S.J., 1982. The Politics of Aging. Power and Policy. Charles C. Thomas, Springfield IL.

Wilson, G.D., 1973. The Psychology of Conservatism. Academic Press, London.

Yang Y., Fu, W.J., Land, K.C.. 2004. A methodological comparison of age-period-cohort models: the intrinsic estimator and conventional generalized linear models. Sociological Methodology 34: 75-110.

Yang Y., Schulhofer-Wohl, S., Fu, W.J., Land, K.C. 2008. The intrinsic estimator for ageperiod-cohort analysis: what it is and how to use it. American Journal of Sociology 114(May): 1697-1736. 
FIGURE 1: $\quad$ Predicted probabilities of Conservative vote choice by coming of age year for three different elections

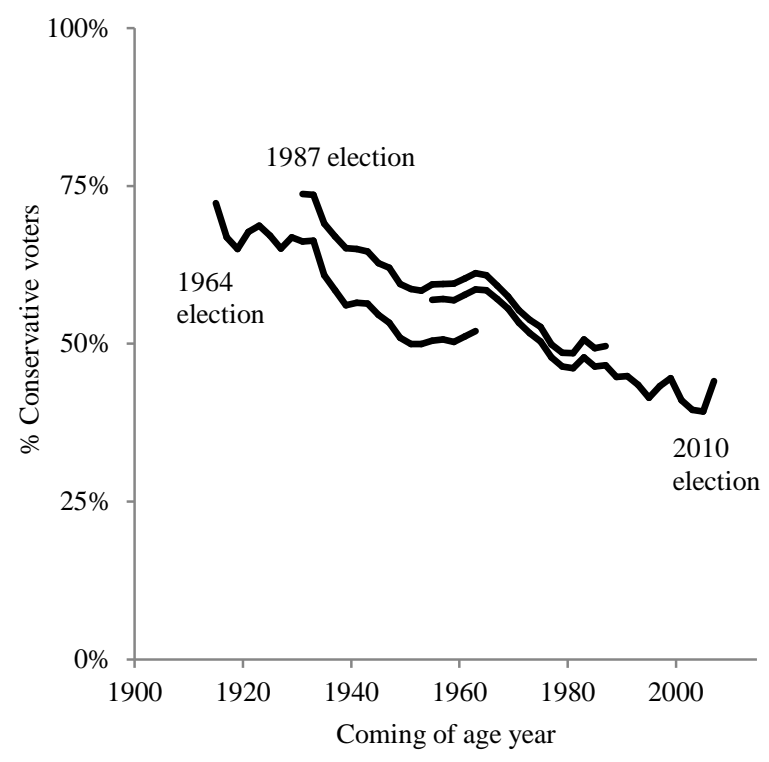

Note: Each line represents the estimated percentage voting Conservative in three different election years based on a multinomial logistic model. The model itself predicts vote choice using the pooled set of twelve British Election Study surveys (see text for details). The lines are 3 period moving averages. 
FIGURE 2: $\quad$ Predicted probabilities of Conservative vote choice by coming of age year for three different elections, holding age effects at their minimum estimated value

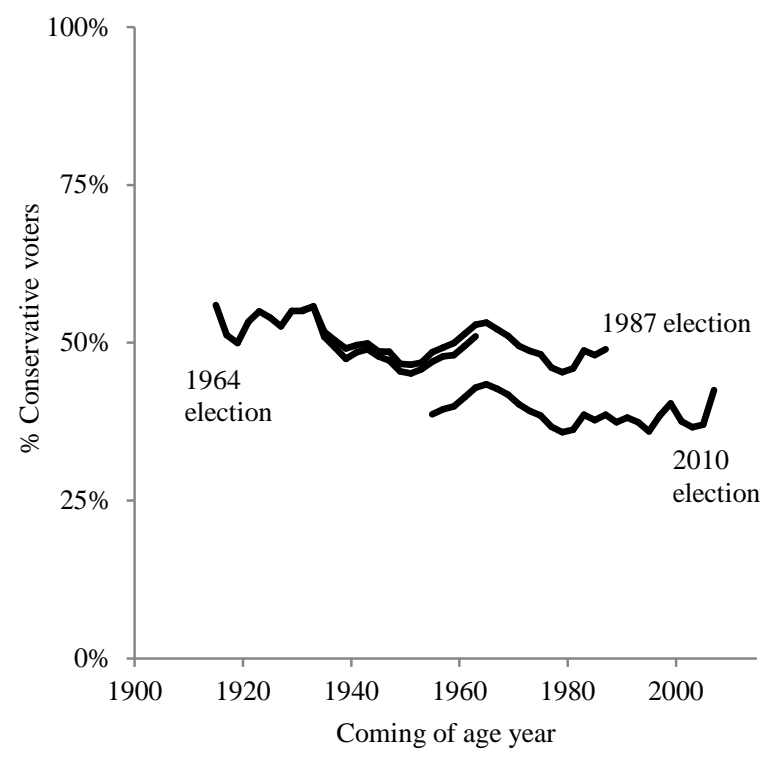

Note: Each line represents the estimated percentage voting Conservative in three different election years based on a multinomial logistic model. The model itself predicts vote choice using the pooled set of twelve British Election Study surveys (see text for details). The lines are 3 period moving averages. 
FIGURE 3: $\quad$ Predicted probabilities of Conservative vote choice by coming of age year for three different elections, holding age effects at their maximum estimated value

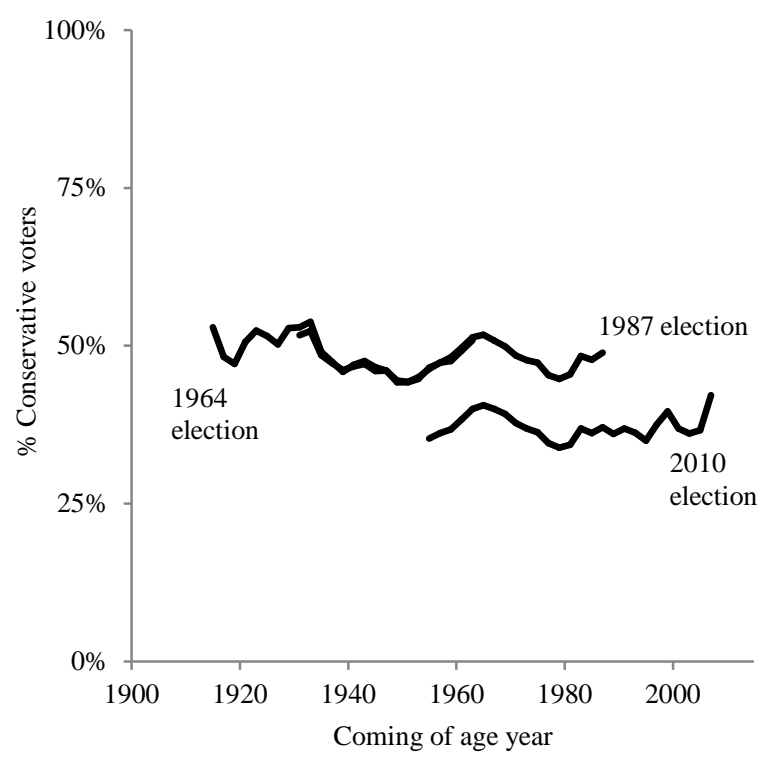

Note: Each line represents the estimated percentage voting Conservative in three different election years based on a multinomial logistic model. The model itself predicts vote choice using the pooled set of twelve British Election Study surveys (see text for details). The lines are 3 period moving averages. 
TABLE 1: $\quad$ Estimates of minimum and maximum per year ageing effects from different panel studies

\begin{tabular}{|c|c|c|c|c|c|c|c|}
\hline \multirow[b]{2}{*}{ Source } & \multirow[b]{2}{*}{ Period (N) } & \multicolumn{3}{|c|}{ Minimum ageing } & \multicolumn{3}{|c|}{ Maximum ageing } \\
\hline & & $\begin{array}{l}\text { Panel } \\
\text { change }\end{array}$ & $\begin{array}{l}\text { Aggregate } \\
\text { change }\end{array}$ & $\begin{array}{l}\text { Ageing } \\
\text { effect }\end{array}$ & $\begin{array}{l}\text { Panel } \\
\text { change }\end{array}$ & $\begin{array}{l}\text { Aggregate } \\
\text { change }\end{array}$ & $\begin{array}{l}\text { Ageing } \\
\text { effect }\end{array}$ \\
\hline BES & $\begin{array}{l}1966-1970 \\
(552)\end{array}$ & & & & 1.90 & 1.43 & 0.47 \\
\hline BES & $\begin{array}{l}1970-1974 \\
(704)\end{array}$ & -1.08 & -2.23 & 1.15 & & & \\
\hline BES & $\begin{array}{l}1974-1979 \\
(589)\end{array}$ & & & & 1.99 & 1.37 & 0.61 \\
\hline BES & $\begin{array}{l}1992-1997 \\
(1105)\end{array}$ & -2.61 & -2.32 & -0.28 & & & \\
\hline BES & $\begin{array}{l}2005-2010 \\
(1665)\end{array}$ & & & & 0.82 & 0.75 & 0.07 \\
\hline NCDS & $\begin{array}{l}1979-2005 \\
(3721)\end{array}$ & -0.18 & -0.44 & 0.26 & & & \\
\hline BHPS & $\begin{array}{l}1992-2005 \\
(2471)\end{array}$ & -0.59 & -0.74 & 0.15 & & & \\
\hline Average & & & & 0.32 & & & 0.38 \\
\hline
\end{tabular}


TABLE A1: Estimates of minimum and maximum per year ageing effects from different panel studies, splitting the NCDS and BHPS studies

\begin{tabular}{|c|c|c|c|c|c|c|c|}
\hline \multirow[b]{2}{*}{ Source } & \multirow[b]{2}{*}{ Period (N) } & \multicolumn{3}{|c|}{ Minimum ageing } & \multicolumn{3}{|c|}{ Maximum ageing } \\
\hline & & $\begin{array}{l}\text { Panel } \\
\text { change }\end{array}$ & $\begin{array}{l}\text { Aggregate } \\
\text { change }\end{array}$ & $\begin{array}{l}\text { Ageing } \\
\text { effect }\end{array}$ & $\begin{array}{l}\text { Panel } \\
\text { change }\end{array}$ & $\begin{array}{l}\text { Aggregate } \\
\text { change }\end{array}$ & $\begin{array}{l}\text { Ageing } \\
\text { effect }\end{array}$ \\
\hline BES & $\begin{array}{l}1966-1970 \\
(552)\end{array}$ & & & & 1.90 & 1.43 & 0.47 \\
\hline BES & $\begin{array}{l}1970-1974 \\
(704)\end{array}$ & -1.08 & -2.23 & 1.15 & & & \\
\hline BES & $\begin{array}{l}1974-1979 \\
(589)\end{array}$ & & & & 1.99 & 1.37 & 0.61 \\
\hline BES & $\begin{array}{l}1992-1997 \\
(1105)\end{array}$ & -2.61 & -2.32 & -0.28 & & & \\
\hline BES & $\begin{array}{l}2005-2010 \\
(1665)\end{array}$ & & & & 0.82 & 0.75 & 0.07 \\
\hline \multirow[t]{2}{*}{ NCDS } & $\begin{array}{l}1979-1997 \\
(4439)\end{array}$ & -0.61 & -0.75 & 0.14 & & & \\
\hline & $\begin{array}{l}1997-2005 \\
(4838)\end{array}$ & & & & 0.74 & 0.25 & 0.48 \\
\hline BHPS & $\begin{array}{l}1992-1997 \\
(3906)\end{array}$ & -2.23 & -2.32 & 0.09 & & & \\
\hline BHPS & $\begin{array}{l}\text { 1997-2005 } \\
(3119)\end{array}$ & & & & 0.57 & 0.25 & 0.32 \\
\hline Average & & & & 0.28 & & & 0.39 \\
\hline
\end{tabular}

